Award Review

\title{
An Overview of a Wide Range of Functions of ZnT and Zip Zinc Transporters in the Secretory Pathway
}

\author{
Taiho KAMBE \\ Division of Integrated Life Science, Graduate School of Biostudies, Kyoto University, \\ Kyoto 606-8502, Japan
}

Online Publication, June 13, 2011

[doi:10.1271/bbb.110056]

\begin{abstract}
Zinc plays essential roles in the early secretory pathway for a number of secretory, membrane-bound, and endosome/lysosome-resident enzymes. It enables the enzymes to fold properly and become functional, by binding as a structural or catalytic component. Moreover, zinc secreted from the secretory vesicles/granules into the extracellular space has a pivotal role as a signaling molecule for various physiological functions. Zinc transporters of the Slc30a/ZnT and Slc39a/Zip families play crucial roles in these functions, mediating zinc influx to and efflux from the lumen of the secretory pathway, constitutively or in a cell-specific manner. This paper reviews current knowledge of the ways these two zinc transporters perform these tasks by manipulating zinc homeostasis in the secretory pathway. Recent questions concerning zinc released into the cytoplasm from the secretory pathway, which then functions as an intracellular signaling molecule, are also briefly reviewed, emphasizing zinc transporter functions.
\end{abstract}

Key words: zinc; Slc30a/ZnT; Slc39a/Zip; secretory pathway; zinc-requiring enzymes

Approximately one-third of all proteins are targeted to the endoplasmic reticulum (ER). ${ }^{1)}$ Thus the early secretory pathway, comprising the ER and the Golgi apparatus, play key roles in regulating the folding, assembly, and transport of newly synthesized proteins, and modification and trafficking during the secretory process. $^{2,3)}$ Various cations are known to help maintain this homeostasis. The major example is the function of calcium in the lumen of the ER, which plays pivotal roles in protein synthesis, folding, and secretion. ${ }^{4)}$ Moreover, cationic essential trace elements are also critical to the secretory pathway. For example, copper is required for the activities of various cuproenzymes, such as multi-copper oxidases (ceruloplasmin/hephaestin) and lysyl oxidase, enzymes prerequisite to iron metabolism and the formation of connective tissues respectively. ${ }^{5)}$ Manganese in the Golgi apparatus is essential for $N$-linked and $O$-linked glycosylation, because most glycosyltransferases require it for their activity. ${ }^{6,7)}$
Among these cations, zinc plays crucial roles in various secretory processes, because it is required for numerous secretory, membrane-bound, and endosome/ lysosome-resident enzymes as an essential component for their catalytic and structural activities. ${ }^{8,9)}$ In addition, the activities of chaperone proteins, which are indispensable for secretory pathway functions, are potentiated by zinc. ${ }^{10,11)}$ Zinc secreted into the extracellular space from the regulated secretory pathway acts as a signaling molecule, ${ }^{12}$ particularly in synaptic neurotransmission. ${ }^{13-15)}$ Thus zinc acts as an active regulator in various cellular processes, rather than being merely a passive binding component of numerous proteins, at least in processes involving the secretory pathway. Therefore, to elucidate how zinc homeostasis and zinc dynamics are maintained in the secretory pathway is of great significance. This review outlines the functions of the zinc transporters involved in the early secretory and the regulated secretory pathways and characterizes their roles at a molecular level.

\section{ZnTs and Zips: Essential Zinc Trans- porters}

Over the last two decades, more than 20 zinc transporters have been identified and characterized. ${ }^{16-19)}$ They are classified into two families: zinc transporter (ZnT: vertebrate cation diffusion facilitator family proteins, Slc30a family) and Zip (Zrt/Irt-like protein, Slc39a family). ${ }^{20-22)}$ Most ZnT transporters are predicted to have six transmembrane domains (TMDs), while Zip transporters have eight TMDs. ZnTs function in zinc efflux from the cytoplasm, while Zips move zinc in the opposite direction. The coordinated action of these two zinc transporters is essential to the maintenance of zinc homeostasis in the cytoplasm, and accumulating evidence indicates that this is also true of the secretory pathway. In fact, nearly half of the characterized proteins of the two families are localized to the early secretory and the regulated secretory pathways (Fig. 1), and they play major roles in the regulation of the pathways.

This review was written in response to the author's receipt of the Japan Society for Bioscience, Biotechnology, and Agrochemistry Award for the Encouragement of Young Scientists in 2010.

Correspondence: Tel: +81-75-753-6273; Fax: +81-75-753-6274; E-mail: kambe1@kais.kyoto-u.ac.jp

Abbreviations: ZnT, zinc transporter; Zip, Zrt/Irt-like protein; TNAP, tissue nonspecific alkaline phosphatase; TMD, transmembrane domain; ER, endoplasmic reticulum; TGN, trans-Golgi network; UPR, unfolded protein response; SNP, single nucleotide polymorphism; KO, knockout 


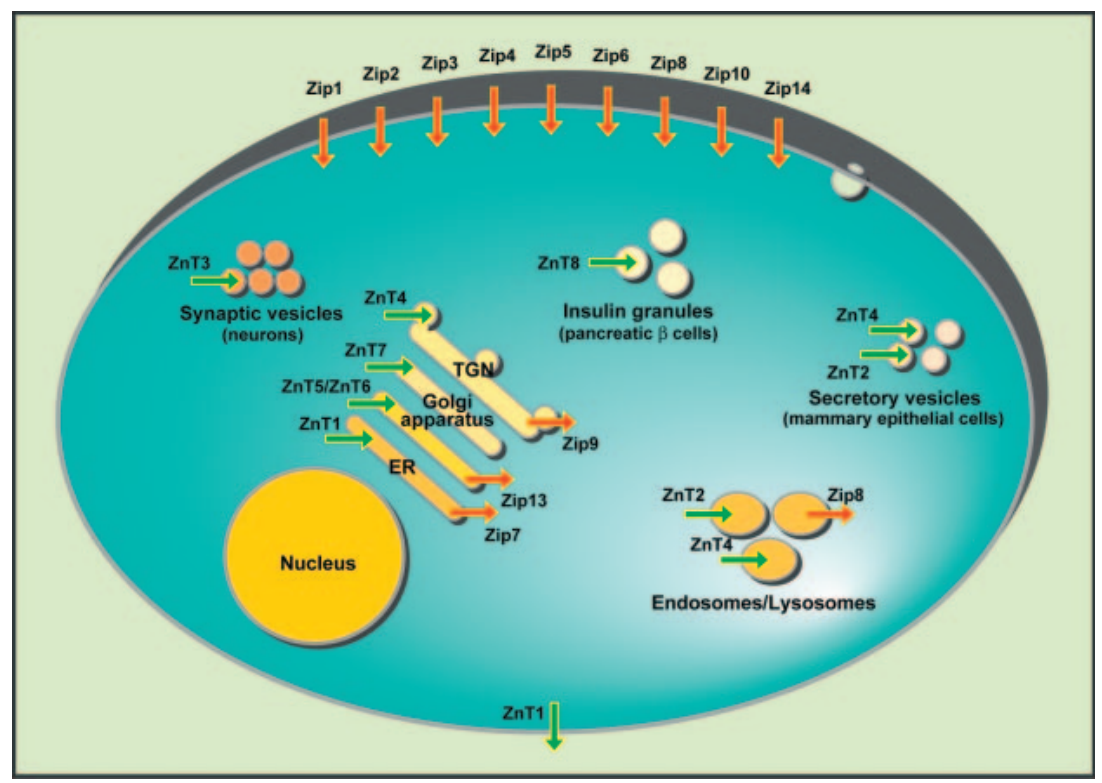

Fig. 1. Subcellular Localization and Direction of Zinc Transport of ZnT and Zip Transporters.

The localizations of ZnT and Zip transporters are shown according to the information available to date. Green and red arrows indicate the direction of zinc mobilization by ZnT and by Zip transporters respectively. Extracellular zinc is taken up by various Zip transporters, and cytoplasmic zinc is mobilized into early secretory compartments such as the endoplasmic reticulum (ER) and Golgi apparatus, and into the regulated secretory pathways such as synaptic vesicles in neurons, insulin granules of pancreatic $\beta$ cells, and secretory vesicles in mammary epithelial cells. Several Zip transporters move zinc out of the secretory pathway. Specific transporters of both families are localized to the endosomes/lysosomes. ZnT5/ZnT6, heterodimers of ZnT5 and ZnT6. TGN, trans-Golgi network. Modified and reproduced with permission. ${ }^{22}$

\section{Survey of ZnTs Localized to the Early Secretory Pathway}

Numerous zinc-requiring enzymes become functional during the secretory process. These include many clinically important enzymes, such as matrix metalloproteinases, which modify the extracellular matrix during development and tumor metastasis, ${ }^{23)}$ angiotensinconverting enzymes, which control blood pressure, ${ }^{24)}$ and alkaline phosphatases, which are essential for bone mineralization, ${ }^{25)}$ and are important markers in clinical evaluation. Thus zinc transporters that move zinc into the lumen of the secretory pathway have significant roles. Of ZnTs localized to the subcellular compartments, ZnT5, ZnT6, and ZnT7 have been identified as locating to the early secretory pathway by virtue of sequence homology to other $\mathrm{ZnT}$ proteins and their homologs (Fig. 1). ${ }^{26-28)}$ Recent studies have addressed their characteristics and functions at a molecular level (Fig. 2), but are far from complete. Their ability to transport zinc into the lumen of the secretory pathway has been deduced from their subcellular localization and studies in several experiments such as zinc transport assay using radioisotope ${ }^{65} \mathrm{Zn}$, growth inhibition analysis using yeast, and zinc-staining analysis using fluorescent zinc probes. ${ }^{26-28)}$ The results suggest that their zinc transport activities are not robust. Consistently with this, overexpression of ZnTs 5, 6, and 7 cannot confer significant resistance to high concentrations of zinc, unlike TGN-resident copper efflux transporters ATP7A and ATP7B, which make cells resistant to high concentrations of copper. ${ }^{29)}$ Moreover, the total cellular zinc contents of cells lacking ZnT5, ZnT6, and ZnT7 are not significantly changed and are similar to that of wild-type cells. ${ }^{30)}$ Thus, they do not operate to sequester or detoxify zinc, unlike ZnT2 and ZnT4, ${ }^{21,31)}$ but are likely to load zinc to zinc-requiring enzymes biosynthesized in the early secretory pathway. Direct evidence to confirm this had been lacking, because overexpression of these ZnTs failed to show any effects on the activities of several zinc-requiring enzymes, but a system developed using DT40 cells, a chicken B lymphocyte-derived cell line, ${ }^{32)}$ overcame this difficulty. Combined gene disruption/re-expression experiments on ZnTs 5-7 using DT40 cells revealed that they are all required for the activation of tissue nonspecific alkaline phosphatase (TNAP), whose activity is wholly dependent on zinc (Fig. 3). That is, TNAP activity in DT40 cells deficient in all of the genes for ZnTs 5-7 decreased significantly. ${ }^{30,33)}$ In the deficient cells, the unfolded protein response (UPR) is exacerbated, as when wild-type DT40 cells are cultured under low zinc conditions, ${ }^{34)}$ probably because misfolding or incomplete assembly of zincrequiring enzymes increases due to decreases in the zinc content, or because residing zinc-dependent chaperone proteins monitoring and assisting protein folding are insufficiently activated. The expression of ZnT5 mRNA is transcriptionally upregulated by the UPR inducer in various cell lines, and this in turn is mediated by transcription factor XBP1 through the conserved TGACGTGG sequence in the $-0.11 \mathrm{~kb}$ promoter region of ZnT5. ${ }^{34)}$ This suggests that zinc homeostasis in the early secretory pathway is strictly maintained by elaborate feedback mechanisms, which control the amount of ZnT5/ZnT6 heterodimers, and this is important to secretory pathway function (Fig. 4).

Combinational re-expression of ZnTs 5-7 and coimmunoprecipitation experiments have indicated that ZnT7 forms homo-oligomers (probably homodimers), while ZnT5 and ZnT6 form heterodimers, activating TNAP in the early secretory pathway (Fig. 3). ${ }^{30,35)}$ The heterodimer formation of ZnT5 and ZnT6 is a unique 


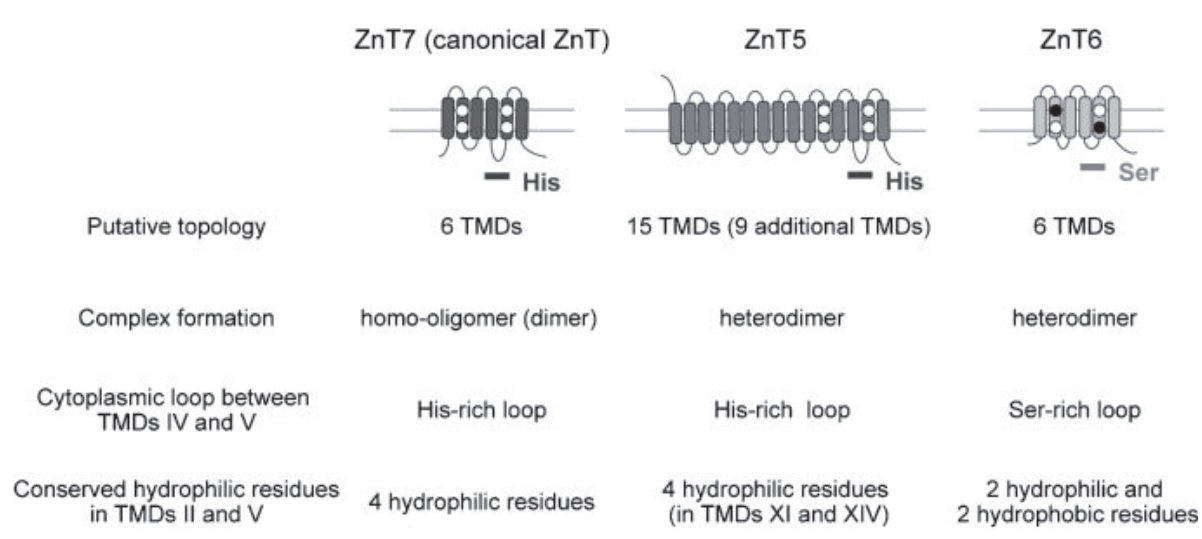

Fig. 2. Characteristics of ZnT5, ZnT6, and ZnT7.

The drawings at the top show the topologies of ZnT5, ZnT6, and ZnT7. ZnT5 and ZnT6 form heterodimers, while ZnT7 form homooligomers. ZnT5 has nine extra transmembrane domains (TMDs) in the long amino-terminal region. ZnT6 has a cytoplasmic Ser-rich loop between TMDs IV and V instead of a His-rich loop and two hydrophobic residues (black dots) in TMD II and V instead of the hydrophilic resides (white dots) in the other ZnTs. ZnT7 is predicted to have a canonical topology, and shows typical characteristics of other ZnT transporters and their homologs. Their characteristics are summarized below.

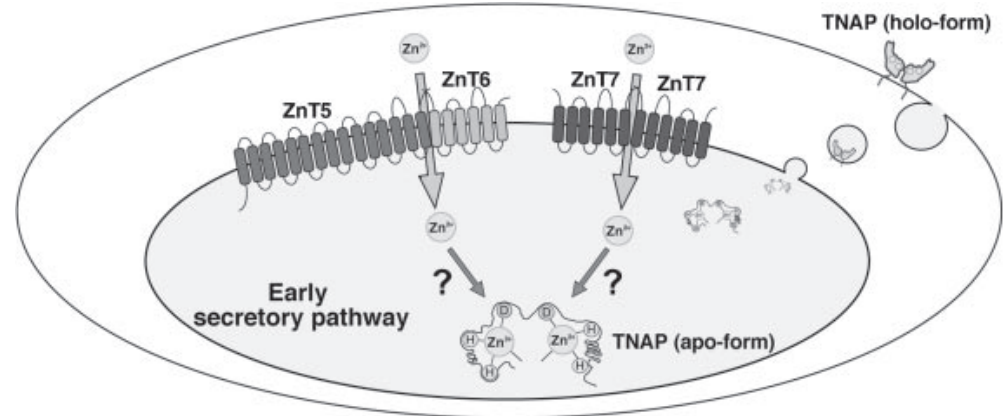

Fig. 3. ZnT5/ZnT6 Heterodimers and ZnT7 Homo-Oligomers Operate to Activate TNAP.

ZnT5/ZnT6 heterodimers and ZnT7 homo-oligomers (probably homodimers) transport zinc into the lumen of the early secretory pathway and then activate zinc-requiring enzymes such as tissue nonspecific alkaline phosphatase (TNAP), although the mechanism of activation subsequent to zinc transport into the lumen remains unknown. TNAP is an ectoenzyme localized to the plasma membrane as a homodimer via a glycophosphatidylinositol anchor, which has two zinc ions in the active site of each monomer.

feature among ZnTs, because all ZnTs, except for ZnT5 and ZnT6, form homo-oligomers (homodimers), considering the demonstration of homodimer formation in the X-ray crystal structure of YiiP, the E. coli ZnT homolog, and the sequence similarity of $\mathrm{ZnT}$ proteins to YiiP. ${ }^{36,37)}$ ZnT5 and ZnT6 have several unique features in their sequences, in addition to heterodimer formation (Fig. 2). ZnT5 has an amino-terminal of nine TMDs fused to the carboxyl-terminal half of six TMDs (corresponding to the full length of the other $\mathrm{ZnT}$ proteins). ${ }^{26}$ This region is not cleaved proteolytically, unlike Zip4, ${ }^{38)}$ and thus is thought to have important functions. However, the long amino-terminal TMD region of ZnT5 is dispensable for cellular functions such as heterodimer formation with ZnT6 and activation of TNAP. Instead, the cytoplasmic carboxyl-terminal tail of ZnT5 is unexpectedly important in determining the binding of ZnT6 as a partner molecule to form heterodimers. ${ }^{35)}$ On the other hand, ZnT6 is unique in that it has a serine (Ser)-rich loop between TMDs IV and $\mathrm{V}$, even though most other ZnTs, including ZnT5, have a histidine (His)-rich loop at that position. The Ser-rich loop is dispensable in the zinc transport activity of the ZnT5/ZnT6 heterodimers, although it probably modulates the activity, in contrast to the indispensability of the His-rich loop of ZnT5. Moreover, ZnT6 is unusual in that it lacks two of the four conserved hydrophilic residues (two for histidine and two for aspartic acid) in TMDs II and V (Fig. 2), ${ }^{28)}$ which are indispensable for zinc transport activity. ${ }^{39)}$ A mutagenesis study of these residues revealed that these conserved positions within TMDs II and V of ZnT6 are not involved in the zincbinding site of the ZnT5/ZnT6 heterodimers, and thus ZnT6 is unlikely to function in zinc transport across the cellular membrane. ${ }^{35)}$ Consistently with this, direct measurements of zinc transport have shown that ZnT5 is an essential component for zinc transport, while ZnT6 is catalytically nonfunctional. ${ }^{40)}$ Further investigation of these unique features should give a clue not only to understand how the ZnT5/ZnT6 heterodimers operate, but also to elucidate the molecular basis of the actions of the other ZnT proteins.

In vertebrates, two zinc transport complexes consisting of ZnT5 and ZnT6 (heterodimers), and ZnT7 (homooligomers) operate in the early secretory pathway. However, genomic studies of other eukaryotes have revealed that the ZnT5/ZnT6 heterodimers are the only complexes that function in most eukaryotes, except for Drosophila. ${ }^{41)}$ In yeasts, the Msc2p/Zrg17p (Saccharomyces cerevisiae) and the Cis4/ZRG17 (Schizosaccharomyces pombe) heterodimers are counterparts of ZnT5/ ZnT6, and play important roles in the early secretory 

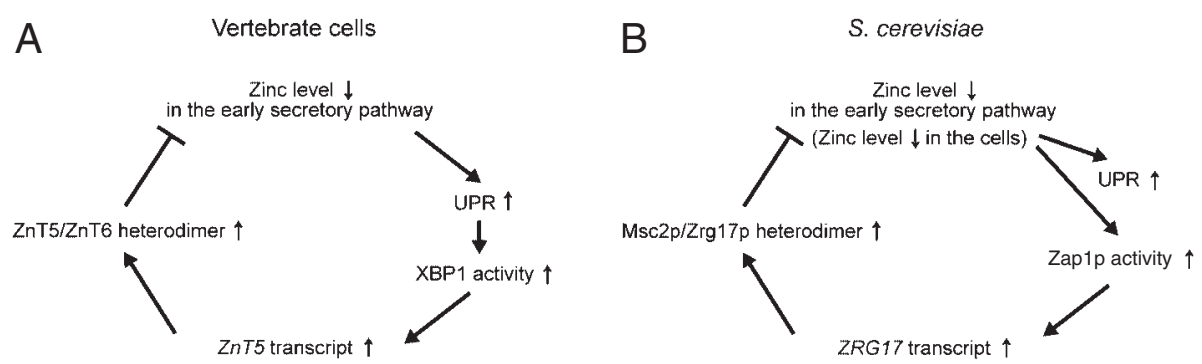

Fig. 4. Model of Feedback Regulation for Homeostatic Maintenance of the Early Secretory Pathway by Zinc, Mediated by ZnT5/ZnT6 Heterodimers and Their Orthologs.

A, Feedback regulation in vertebrate cells. Zinc deficiency induces an unfolded protein response (UPR), ${ }^{34,44)}$ which activates transcription factor XBP1. XBP1 increases ZnT5 transcription, leading to increases in ZnT5/ZnT6 heterodimers, which enhances the zinc supply into the early secretory pathway and thus decreases the UPR. B, Feedback regulation in S. cerevisiae. Zinc deficiency induces an UPR, as in vertebrate cells, ${ }^{44)}$ and activates zinc-responsive transcriptional activator Zap1p. Zap1p upregulates ZRG17 transcription, ${ }^{104)}$ leading to increases in Msc2p/Zrg17p heterodimers, ${ }^{42)}$ which enhance the zinc supply into the ER, where these heterodimers are located. Note that similar feedback loops operate both in vertebrate cells and in S. cerevisiae, while the molecular mechanism is quite different.

pathway; they are required for proper functioning of the $\mathrm{ER}^{42)}$ and for Golgi membrane trafficking. ${ }^{43)}$ Moreover, yeast strains lacking these complexes are defective in ER-associated degradation and show increased UPR. ${ }^{42,44)}$ Thus the cellular functions of the ZnT5/ ZnT6 heterodimers in the homeostatic maintenance of secretory pathway functions are conserved in evolution.

The heterodimer formation of ZnT5/ZnT6 appears to be somewhat strict in a species-specific manner. Coexpression of human ZnT5 and ZnT6 is required to complement the growth defects of $m s c 2$ or $\mathrm{zrg} 17$ mutant yeasts functionally. Despite that, expression of either fails to do so. ${ }^{42)}$ Similarly, co-expression of Caenorhabditis elegans ZnT5 and ZnT6 (toc-1) restores TNAP activity in DT40 cells lacking ZnTs 5-7 to an extent similar to human ZnT5/ZnT6 heterodimers, but coexpression of human ZnT5 and C. elegans ZnT6 (toc-1) or vice versa fails to do so (unpublished data). Coexpression of human ZnT5 and chicken ZnT6 and vice versa restores TNAP activity, ${ }^{33)}$ suggesting that these vertebrate proteins are mutually compatible. Although there are no satisfactory data on physical interactions between them, one possible reason for this speciesspecific manner of action is the sequence diversity of the cytoplasmic carboxyl-terminal tail among ZnT5 and its orthologs. ${ }^{35)}$ It should be interesting to investigate how the ZnT5/ZnT6 complexes changed evolutionarily while retaining their fundamental cellular functions. Furthermore, it is important to elucidate how the redundant functions and independent functions of zinc mediated by the ZnT5/ZnT6 and ZnT7 complexes are discriminated in the early secretory pathway, because ZnT5 and ZnT7 knockout (KO) mice show somewhat different phenotypes, although these discrepancies can be attributed to the differences in their expression patterns. $^{45-47)}$

$\mathrm{ZnT1}$ is known to locate predominantly to the plasma membrane, ${ }^{48)}$ but recently it was shown to locate to the ER by forming complexes with EVER proteins in human keratinocytes. The complexes affect intracellular zinc distribution and downregulate transcription factors stimulated by MTF1, c-Jun, and Elk. ${ }^{49)}$ This suggests that ZnT1 can also function to regulate the zinc contents in the early secretory pathway. Further investigation is required to clarify its participation in zinc homeostasis in the early secretory pathway.

\section{Survey of ZnTs Localized to Vesicles/ Granules in the Regulated Secretory Path- way}

Whereas ZnT5, ZnT6, and ZnT7 play important roles in the early secretory pathway, other ZnT transporters also function in physiologically important roles in a cellspecific manner. ${ }^{16,19,22)}$ Among vertebrates, some highly specialized cell types have cytoplasmic vesicles/granules accumulating high zinc contents. For example, pancreatic $\beta$ cells, ${ }^{50)}$ specialized glutamatergic neurons, ${ }^{51)}$ epithelial cells of the lateral prostate, ${ }^{52)}$ pigment epithelial cells in the retina, ${ }^{53,54)}$ granular convoluted tubule cells of submaxillary gland, ${ }^{55)}$ pituitary secretory cells, ${ }^{56)}$ sperm cells, ${ }^{57,58)}$ mast cells ${ }^{59,60)}$ and secreting mammary epithelial cells ${ }^{61)}$ are known to have zinccontaining vesicles/granules. These are controlled as part of the regulated secretory pathway, and hence specialized specific zinc transporters must be in operation. Some ZnT transporters contribute to zinc supply in the lumen of the vesicles/granules. Below, three major questions concerning the regulated secretory pathways involving $\mathrm{ZnT}$ transporters and zinc are reviewed: pancreatic $\beta$ cells, glutamatergic neurons and mammary epithelial cells.

\section{Pancreatic $\beta$ cells}

Zinc in pancreatic $\beta$ cells plays a crucial role in facilitating zinc-proinsulin hexamer formation just after export from the ER, and subsequently crystal formation after proteolytic conversion from proinsulin to insulin in insulin granules. ${ }^{62)}$ Zinc-insulin crystals play a key role in the storage and maturation of insulin at supersaturating concentrations, ensuring appropriate insulin secretion. Zinc released from $\beta$ cells along with insulin performs important paracrine and autocrine functions in $\alpha$ cells (inhibition of glucagon secretion) ${ }^{63)}$ and in $\beta$ cells (contribution to cell death). ${ }^{64)}$ This indicates that zinc-insulin crystal formation in insulin granules is also important to the homeostatic maintenance of pancreatic islets, and that zinc transporters fulfill a pivotal role in $\beta$ cells. Among the many zinc transporters expressed in pancreatic islets, ZNT5 was first identified as a ZnT associated with insulin granules in $\beta$ cells, ${ }^{26)}$ which suggests that it contributes to the formation of zincinsulin crystals. However, direct observation of the 

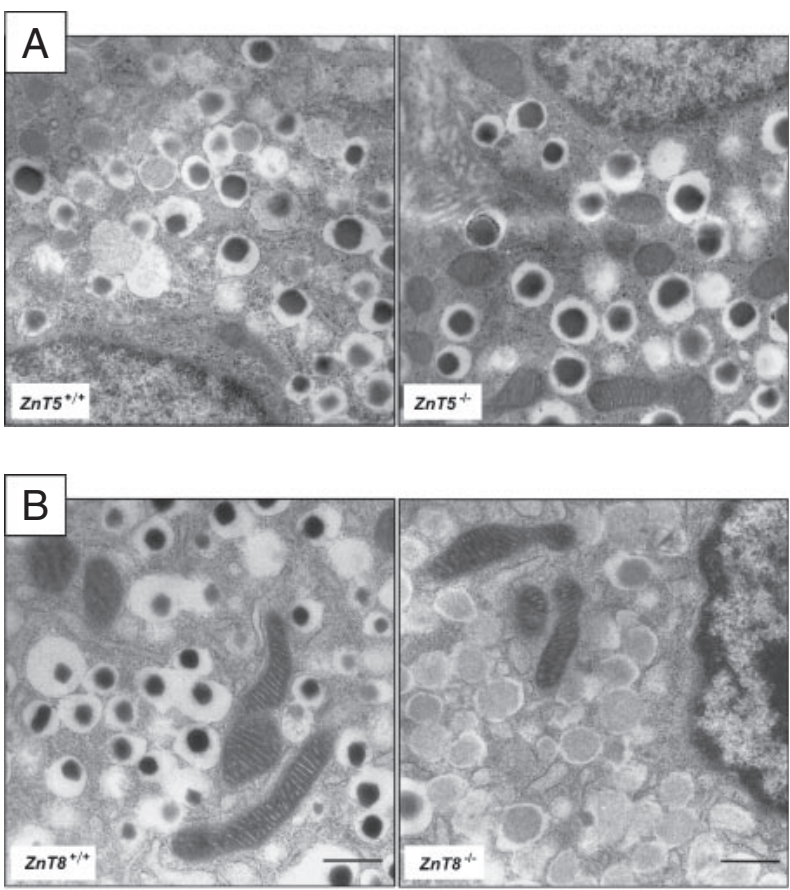

Fig. 5. Transmission Electron Microscopy of Pancreatic $\beta$ Cells of ZnT Transporter Gene Knockout Mice.

A, Insulin granules of $Z n T 5^{-/-}$pancreatic $\beta$ cells (right panel) show electron dense cores, as in the control $Z n T 5^{+/+} \beta$ cells (left panel). Electron microscopic analysis of $\beta$ cells was performed as described previously. $\left.{ }^{26}\right) \mathrm{B}$, Insulin granules of $\mathrm{ZnT}^{-/-} \beta$ cells (right panel) lack the electron dense cores in contrast to the control cells (left panel). The lower panels are reproduced with permission. ${ }^{74}$

crystals in $\beta$ cells in vivo in ZnT5-KO mice showed normal dense cores composed of zinc-insulin crystals in insulin granules (Fig. 5A), even though these mice showed malfunctions in other tissues and cells. ${ }^{45,46)}$ Thus ZnT5 is not significantly involved in zinc-insulin crystal formation in $\beta$ cells. Instead, it must be important to the zinc supply into the early secretory pathway in $\beta$ cells, ${ }^{65)}$ with ZnT6, as described above (see Fig. 3).

In terms of zinc transporters and diabetes, ZNT8, the highly $\beta$ cell-specific $\mathrm{ZnT}$, is now receiving the most attention, because of its involvement in the etiology of both type- 1 and type- 2 diabetes. ${ }^{66,67)}$ The nonsynonymous single nucleotide polymorphism (SNP) of the ZNT8 gene (rs13266634) is reported to be associated with high risk of type-2 diabetes. ${ }^{68-71)}$ In ZnT8KO mice, the zinc contents of $\beta$ cells decreased significantly and the dense core of zinc-insulin crystals is lost (Fig. 5B), indicating that ZnT8 is indispensable for zinc-insulin crystal formation. ${ }^{65,72-74)}$ ZnT8-KO mice display abnormalities in glucose tolerance, insulin processing and secretion, and body weight, although several discrepancies are present among these mice, probably because of differences in age and diet as well as strain. ${ }^{65,72-74)}$ The association with type-2 diabetes and the results of $\mathrm{KO}$ mouse studies indicate that $\mathrm{ZnT} 8$ plays an indispensable role in $\beta$-cell functions by transporting zinc into insulin granules. In addition, ZnT8 is now receiving attention as a type-1 diabetes autoimmunity marker, ${ }^{75}$ and a recent report explains that the rs13266634 SNP determines ZNT8 autoantibody specificity. ${ }^{76}$

\section{Glutamatergic neurons}

Zinc plays pivotal roles in the brain's functions, because synaptically released zinc interacts with various neuronal ion channels, transporters, and receptors, and modulates synaptic transmission and plasticity. ${ }^{13,14)}$ ZnT3 is a critical transporter of zinc into the synaptic vesicles of glutamatergic neurons in the hippocampus and neocortex ${ }^{77)}$ and ZnT3-KO mice showed depletion of synaptic vesicular zinc contents. ${ }^{78)}$ Unlike other $\mathrm{ZnT}$ transporters that transport zinc as $\mathrm{Zn}^{2+} / \mathrm{H}^{+}$exchangers, ${ }^{40)}$ the zinc transport activity of ZnT3 is increased by vesicular glutamate transporter 1 expression, ${ }^{79)}$ and thus its trafficking to the synaptic vesicles by a brain-specific form of the AP-3 adaptor protein is essential for the activity. ${ }^{80,81)} \mathrm{ZnT} 3$ has received attention not only in terms of zinc physiology in the brain, but also pathogenesis, because zinc released from synaptic vesicles is implicated in $\beta$-amyloid plaque formation, and the expression levels of ZnT3 might be an important factor in the onset of Alzheimer's disease. ${ }^{82)}$ Young ZnT3-KO mice do not show impairment in spatial learning, memory, or sensorimotor functions, ${ }^{78)}$ whereas older ZnT3-KO mice (over 6 months) exhibit age-dependent deficits in learning and memory associated with significant decreases in various hippocampal proteins. ${ }^{83)}$ The expression level of $\mathrm{ZnT3}$ falls with age in mice and healthy older humans, ${ }^{83)}$ and thus synaptic zinc mediated by ZnT3 might be required to prevent aging-related deficits in learning and memory.

\section{Mammary epithelial cells}

The zinc in breast milk is essential for the growth and health of neonates. ${ }^{84,85)}$ Milk zinc concentrations are considerably higher than those in the serum, suggesting that effective machinery for zinc uptake and subsequent secretion into milk is present in mammary epithelial cells. A heterozygous mutation in the human ZNT2 gene was found in women with low zinc concentrations in the milk, leading to transient zinc deficiency and dermatitis in the nursing child, ${ }^{86}$ ) indicating that $\mathrm{ZnT} 2$, first identified as a protein involved in zinc transport into endosomes/lysosomes, ${ }^{31)}$ is also employed in the important function of transporting zinc into breast milk. A similar low zinc-secreting phenotype was found in a mouse with a loss-of-function mutation in the ZnT4 gene. ${ }^{87)}$ The lethal milk (lm) homozygous dam produces zinc-deficient milk so that pups suckling from her die before weaning due to zinc deficiency. ${ }^{88)}$ Thus ZnT4 is important for zinc transport into the milk in the mouse, although there have been no reports indicating mutations in the ZNT4 gene in women with low zinc breast milk. Lack of zinc in the submaxillary gland of $l \mathrm{~m} / \mathrm{lm}$ mice is described in one review, ${ }^{21)}$ suggesting that ZnT4 plays a role in zinc transport in the exocrine glands.

\section{Survey of Zips Localized to the Secre- tory Pathway}

Because Zip transporters mobilize zinc in the opposite direction to ZnT transporters, ${ }^{20)}$ their functions in the secretory pathway are likely to decrease zinc contents, and thus probably act in fine tuning of the activity of various zinc-requiring enzymes, although bidirectional zinc transport dependent on zinc status has been found 
in the yeast Zip7 homolog (Yke4p), located in the ER. ${ }^{89)}$ In fact, Zip9 in the Golgi apparatus plays a modulatory role in the activation of TNAP, which is probably reciprocal to the functions of ZnT5/ZnT6 and ZnT7 transport complexes. ${ }^{90)}$ In addition to Zip9, Zip7 and Zip13 are known to locate to the early secretory pathway and to regulate zinc contents in the lumen of the Golgi apparatus, ${ }^{91,92)}$ suggesting that both Zip transporters also play modulatory roles in the activity of zinc-requiring enzymes, like Zip9.

Emerging evidence indicates that zinc released into the cytoplasm from the early secretory pathway fulfills critical functions as an intracellular signaling molecule in various cellular events. ${ }^{12,93,94)}$ The phenomenon of zinc release from the perinuclear area including the ER is called the zinc wave. ${ }^{95}$ The mechanism of zinc release has not been elucidated, but these findings have drawn particular attention to Zip transporters localized to the early secretory pathway. ${ }^{96)}$ Indeed, Zip7-mediated intracellular zinc contributes to growth factor signaling in cancer cells, ${ }^{97)}$ and Zip13 is involved in the BMP/ TGF- $\beta$ signaling pathways by controlling the nuclear localization of Smad proteins. ZIP13 is required for connective tissue development, and hence a loss-offunction point mutation in the ZIP13 gene causes Ehlers-Danlos syndrome. ${ }^{92,98)}$ These lines of evidence suggest that zinc mediated by ZnT transporters and stored in the early secretory pathway is released by Zip transporters and has various cellular functions. This might explain why ZnT5 is involved in cytoplasmic signaling in mast cells via regulation of the translocation of protein kinase $\mathrm{C}$ to the plasma membrane, which is required for late-phase allergic responses. ${ }^{46)}$ To date there have been no reports describing Zip transporter functions related to the cytoplasmic vesicles/granules of the regulated secretory pathway.

\section{Perspectives}

How zinc proteins capture zinc is a major question. Zinc insertion into zinc proteins might occur via zincmediated protein/protein interactions, that is, without zinc ever being free (the associative mechanism) or via free zinc ions (the dissociative mechanism), ${ }^{99)}$ but its molecular basis is unclear. Because there were estimated to be about 3000 zinc-binding proteins (almost $10 \%$ of total proteins) by a recent metalloproteome study, ${ }^{100)}$ chaperone proteins are unlikely to operate in zinc insertion in most cases, unlike other metals. ${ }^{101,102)}$ However, unique zinc insertion mechanisms might operate in the lumen of the early secretory pathway, which is more oxidative than the cytoplasm. Hence it is important to clarify the zinc insertion mechanism in the early secretory pathway, subsequent to zinc transport by $\mathrm{ZnT}$ complexes. On the other hand, it is also important to elucidate how cytoplasmic vesicles/granules accumulate high levels of zinc in the regulated secretory pathway. In bacteria, compartmentalization of a metal is an elaborate mechanism enabling metalloproteins to receive the correct metal at the correct location. ${ }^{103)}$ Similar mechanisms might operate for zinc in the secretory pathway in a more complicated manner. Thus, it must be determined (i) when, where, and how in the secretory pathway ZnT and Zip transporters monitor zinc concentrations and control the influx and efflux of zinc, and (ii) when, where, and how in the secretory pathway zinc-requiring proteins capture and dissociate zinc mediated by ZnT and Zip transporters. The answers to these questions should help to clarify the points listed above and to make possible a better understanding of the molecular mechanisms of zinc dynamics, including zinc signaling, leading to new research areas in the field of zinc biology.

\section{Acknowledgments}

I would like to express my sincere gratitude to Dr. Ryuzo Sasaki, Professor Emeritus of Kyoto University, for his gentle guidance and courteous encouragement. I would like to express my sincere thanks to Dr. Glen K. Andrews, Distinguished Professor of the University of Kansas Medical Center, for kind guidance and valuable discussion. I thank Dr. Masaya Nagao, Professor of Kyoto University, for encouragement and helpful discussion. And I thank Dr. Hiroshi Narita, Professor of Kyoto Women's University, Dr. Seiji Masuda, Associate Professor of Kyoto University, and Dr. Michael J. Petris, Associate Professor of the University of Missouri, Columbia, for encouragement and support. I would also like to thank the late Dr. Yuko Yamaguchi-Iwai, Associate Professor of Kyoto University, for her guidance and encouragement throughout this research. I also thank all my collaborators in this research, and the members of the Laboratory of Biosignals and Response, Graduate School of Biostudies, Kyoto University, for helpful advice and technical support. I thank Dr. Toshihiko Iwanaga for permitting the use of an electron micrograph of pancreatic $\beta$ cells of $\mathrm{ZnT}^{-/-}$mice, Dr. Yusuke Nakamura and Dr. Toshihiro Tanaka for providing $\mathrm{ZnT5}^{-/-}$mice, and Dr. Frans Schuit for permitting the use of his photomicrographs of the $\beta$ cells of $\mathrm{ZnT}^{-/-}$mice. This work was supported by Grantsin-Aid from the Ministry of Education, Culture, Sports, Science, and Technology of Japan.

\section{Addendum-Recently}

Qin et al. (Proc. Natl. Acad. Sci. USA, 108, 73517356 (2011)) measured the steady-state zinc levels and zinc flux in the ER and Golgi apparatus by the use of genetically encoded zinc, and estimated free zinc concentrations in both organelles to be just under $1 \mathrm{pM}$.

\section{References}

1) Vembar SS and Brodsky JL, Nat. Rev. Mol. Cell Biol., 9, 944957 (2008).

2) Ellgaard L and Helenius A, Nat. Rev. Mol. Cell Biol., 4, 181191 (2003).

3) Trombetta ES and Parodi AJ, Annu. Rev. Cell Dev. Biol., 19, 649-676 (2003).

4) Corbett EF and Michalak M, Trends Biochem. Sci., 25, 307311 (2000).

5) Lutsenko S, Barnes NL, Bartee MY, and Dmitriev OY, Physiol. Rev., 87, 1011-1046 (2007).

6) Kaufman RJ, Swaroop M, and Murtha-Riel P, Biochemistry, 33, 9813-9819 (1994).

7) Breton C, Snajdrova L, Jeanneau C, Koca J, and Imberty A, Glycobiology, 16, 29R-37R (2006).

8) Vallee BL and Falchuk KH, Physiol. Rev., 73, 79-118 (1993). 
9) Coleman JE, Annu. Rev. Biochem., 61, 897-946 (1992).

10) Leach MR, Cohen-Doyle MF, Thomas DY, and Williams DB, J. Biol. Chem., 277, 29686-29697 (2002).

11) Solovyov A and Gilbert HF, Protein Sci., 13, 1902-1907 (2004).

12) Hershfinkel M, Top. Curr. Genet., 14, 131-153 (2006).

13) Frederickson CJ, Koh JY, and Bush AI, Nat. Rev. Neurosci., 6, 449-462 (2005)

14) Sensi SL, Paoletti P, Bush AI, and Sekler I, Nat. Rev. Neurosci., 10, 780-791 (2009).

15) Takeda A, Brain Res. Rev., 34, 137-148 (2000).

16) Lichten LA and Cousins RJ, Annu. Rev. Nutr., 29, 153-176 (2009).

17) Eide DJ, Biochim. Biophys. Acta, 1763, 711-722 (2006).

18) Sekler I, Sensi SL, Hershfinkel M, and Silverman WF, Mol. Med., 13, 337-343 (2007).

19) Kambe T, Weaver BP, and Andrews GK, Genesis, 46, 214228 (2008).

20) Eide DJ, Pflugers Arch., 447, 796-800 (2004).

21) Palmiter RD and Huang L, Pflugers Arch., 447, 744-751 (2004).

22) Kambe T, Yamaguchi-Iwai Y, Sasaki R, and Nagao M, Cell. Mol. Life Sci., 61, 49-68 (2004).

23) Chang C and Werb Z, Trends Cell Biol., 11, S37-S43 (2001).

24) Turner AJ and Hooper NM, Trends Pharmacol. Sci., 23, 177183 (2002).

25) Zurutuza L, Muller F, Gibrat JF, Taillandier A, Simon-Bouy B, Serre JL, and Mornet E, Hum. Mol. Genet., 8, 1039-1046 (1999).

26) Kambe T, Narita H, Yamaguchi-Iwai Y, Hirose J, Amano T, Sugiura N, Sasaki R, Mori K, Iwanaga T, and Nagao M, J. Biol. Chem., 277, 19049-19055 (2002).

27) Kirschke CP and Huang L, J. Biol. Chem., 278, 4096-4102 (2003).

28) Huang L, Kirschke CP, and Gitschier J, J. Biol. Chem., 277, 26389-26395 (2002).

29) Petris MJ, Mercer JF, Culvenor JG, Lockhart P, Gleeson PA, and Camakaris J, EMBO J., 15, 6084-6095 (1996).

30) Suzuki T, Ishihara K, Migaki H, Nagao M, Yamaguchi-Iwai Y, and Kambe T, J. Biol. Chem., 280, 30956-30962 (2005).

31) Palmiter RD, Cole TB, and Findley SD, EMBO J., 15, 1784 1791 (1996).

32) Buerstedde JM and Takeda S, Cell, 67, 179-188 (1991).

33) Suzuki T, Ishihara K, Migaki H, Matsuura W, Kohda A, Okumura K, Nagao M, Yamaguchi-Iwai Y, and Kambe T, J. Biol. Chem., 280, 637-643 (2005).

34) Ishihara K, Yamazaki T, Ishida Y, Suzuki T, Oda K, Nagao M, Yamaguchi-Iwai Y, and Kambe T, J. Biol. Chem., 281, 17743-17750 (2006).

35) Fukunaka A, Suzuki T, Kurokawa Y, Yamazaki T, Fujiwara N, Ishihara K, Migaki H, Okumura K, Masuda S, Yamaguchi-Iwai Y, Nagao M, and Kambe T, J. Biol. Chem., 284, 30798-30806 (2009).

36) Lu M and Fu D, Science, 317, 1746-1748 (2007).

37) Lu M, Chai J, and Fu D, Nat. Struct. Mol. Biol., 16, 1063 1067 (2009).

38) Kambe $\mathrm{T}$ and Andrews GK, Mol. Cell. Biol., 29, 129-139 (2009).

39) Montanini B, Blaudez D, Jeandroz S, Sanders D, and Chalot M, BMC Genomics, 8, 107 (2007).

40) Ohana E, Hoch E, Keasar C, Kambe T, Yifrach O, Hershfinkel M, and Sekler I, J. Biol. Chem., 284, 17677-17686 (2009).

41) Kambe T, Suzuki T, Nagao M, and Yamaguchi-Iwai Y, Genomics Proteomics Bioinformatics, 4, 1-9 (2006).

42) Ellis CD, Macdiarmid CW, and Eide DJ, J. Biol. Chem., 280, 28811-28818 (2005).

43) Fang Y, Sugiura R, Ma Y, Yada-Matsushima T, Umeno H, and Kuno T, Mol. Biol. Cell, 19, 1295-1303 (2008).

44) Ellis CD, Wang F, MacDiarmid CW, Clark S, Lyons T, and Eide DJ, J. Cell Biol., 166, 325-335 (2004).

45) Inoue $K$, Matsuda $K$, Itoh $M$, Kawaguchi $H$, Tomoike $H$, Aoyagi T, Nagai R, Hori M, Nakamura Y, and Tanaka T, Hum. Mol. Genet., 11, 1775-1784 (2002).
46) Nishida K, Hasegawa A, Nakae S, Oboki K, Saito H, Yamasaki S, and Hirano T, J. Exp. Med., 206, 1351-1364 (2009).

47) Huang L, Yu YY, Kirschke CP, Gertz ER, and Lloyd KK, J. Biol. Chem., 282, 37053-37063 (2007).

48) Palmiter RD and Findley SD, EMBO J., 14, 639-649 (1995).

49) Lazarczyk M, Pons C, Mendoza JA, Cassonnet P, Jacob Y, and Favre M, J. Exp. Med., 205, 35-42 (2008).

50) Zalewski PD, Millard SH, Forbes IJ, Kapaniris O, Slavotinek A, Betts WH, Ward AD, Lincoln SF, and Mahadevan I, J. Histochem. Cytochem., 42, 877-884 (1994).

51) Cole TB, Wenzel HJ, Kafer KE, Schwartzkroin PA, and Palmiter RD, Proc. Natl. Acad. Sci. USA, 96, 1716-1721 (1999).

52) Sorensen MB, Stoltenberg M, Juhl S, Danscher G, and Ernst E, Prostate, 31, 125-130 (1997).

53) Akagi T, Kaneda M, Ishii K, and Hashikawa T, J. Histochem. Cytochem., 49, 87-96 (2001).

54) Leung KW, Liu M, Xu X, Seiler MJ, Barnstable CJ, and Tombran-Tink J, Invest. Ophthalmol. Vis. Sci., 49, 1221-1231 (2008).

55) Frederickson CJ, Perez-Clausell J, and Danscher G, J. Histochem. Cytochem., 35, 579-583 (1987).

56) Thorlacius-Ussing O, Neuroendocrinology, 45, 233-242 (1987).

57) Andrews JC, Nolan JP, Hammerstedt RH, and Bavister BD, Cytometry, 21, 153-159 (1995).

58) Danscher $\mathrm{G}$ and Zimmer J, Histochemistry, 55, 27-40 (1978).

59) Danscher G, Obel J, and Thorlacius-Ussing O, Histochemistry, 66, 293-300 (1980).

60) Ho LH, Ruffin RE, Murgia C, Li L, Krilis SA, and Zalewski PD, J. Immunol., 172, 7750-7760 (2004).

61) Lopez V and Kelleher SL, Biochem. J., 422, 43-52 (2009).

62) Dodson G and Steiner D, Curr. Opin. Struct. Biol., 8, 189-194 (1998).

63) Ishihara $\mathrm{H}$, Maechler $\mathrm{P}$, Gjinovci $\mathrm{A}$, Herrera PL, and Wollheim CB, Nat. Cell Biol., 5, 330-335 (2003).

64) Kim BJ, Kim YH, Kim S, Kim JW, Koh JY, Oh SH, Lee MK, Kim KW, and Lee MS, Diabetes, 49, 367-372 (2000).

65) Wijesekara N, Dai FF, Hardy AB, Giglou PR, Bhattacharjee A, Koshkin V, Chimienti F, Gaisano HY, Rutter GA, and Wheeler MB, Diabetologia, 53, 1656-1668 (2010).

66) Chimienti F, Devergnas S, Favier A, and Seve M, Diabetes, 53, 2330-2337 (2004).

67) Chimienti F, Favier A, and Seve M, Biometals, 18, 313-317 (2005).

68) Sladek R, Rocheleau G, Rung J, Dina C, Shen L, Serre D, Boutin P, Vincent D, Belisle A, Hadjadj S, Balkau B, Heude B, Charpentier G, Hudson TJ, Montpetit A, Pshezhetsky AV, Prentki M, Posner BI, Balding DJ, Meyre D, Polychronakos C, and Froguel P, Nature, 445, 881-885 (2007).

69) Saxena R, Voight BF, Lyssenko V, Burtt NP, de Bakker PI, Chen H, Roix JJ, Kathiresan S, Hirschhorn JN, Daly MJ, Hughes TE, Groop L, Altshuler D, Almgren P, Florez JC, Meyer J, Ardlie K, Bengtsson Bostrom K, Isomaa B, Lettre G, Lindblad U, Lyon HN, Melander O, Newton-Cheh C, Nilsson P, Orho-Melander M, Rastam L, Speliotes EK, Taskinen MR, Tuomi T, Guiducci C, Berglund A, Carlson J, Gianniny L, Hackett R, Hall L, Holmkvist J, Laurila E, Sjogren M, Sterner M, Surti A, Svensson M, Tewhey R, Blumenstiel B, Parkin M, Defelice M, Barry R, Brodeur W, Camarata J, Chia N, Fava M, Gibbons J, Handsaker B, Healy C, Nguyen K, Gates C, Sougnez C, Gage D, Nizzari M, Gabriel SB, Chirn GW, Ma Q, Parikh H, Richardson D, Ricke D, and Purcell S, Science, 316, 1331-1336 (2007).

70) Zeggini E, Weedon MN, Lindgren CM, Frayling TM, Elliott KS, Lango H, Timpson NJ, Perry JR, Rayner NW, Freathy RM, Barrett JC, Shields B, Morris AP, Ellard S, Groves CJ, Harries LW, Marchini JL, Owen KR, Knight B, Cardon LR, Walker M, Hitman GA, Morris AD, Doney AS, McCarthy MI, and Hattersley AT, Science, 316, 1336-1341 (2007).

71) Scott LJ, Mohlke KL, Bonnycastle LL, Willer CJ, Li Y, Duren 
WL, Erdos MR, Stringham HM, Chines PS, Jackson AU, Prokunina-Olsson L, Ding CJ, Swift AJ, Narisu N, Hu T, Pruim R, Xiao R, Li XY, Conneely KN, Riebow NL, Sprau AG, Tong M, White PP, Hetrick KN, Barnhart MW, Bark CW, Goldstein JL, Watkins L, Xiang F, Saramies J, Buchanan TA, Watanabe RM, Valle TT, Kinnunen L, Abecasis GR, Pugh EW, Doheny KF, Bergman RN, Tuomilehto J, Collins FS, and Boehnke M, Science, 316, 1341-1345 (2007).

72) Pound LD, Sarkar SA, Benninger RK, Wang Y, Suwanichkul A, Shadoan MK, Printz RL, Oeser JK, Lee CE, Piston DW, McGuinness OP, Hutton JC, Powell DR, and O'Brien RM, Biochem. J., 421, 371-376 (2009).

73) Nicolson TJ, Bellomo EA, Wijesekara N, Loder MK, Baldwin JM, Gyulkhandanyan AV, Koshkin V, Tarasov AI, Carzaniga R, Kronenberger K, Taneja TK, da Silva Xavier G, Libert S, Froguel P, Scharfmann R, Stetsyuk V, Ravassard P, Parker H, Gribble FM, Reimann F, Sladek R, Hughes SJ, Johnson PR, Masseboeuf M, Burcelin R, Baldwin SA, Liu M, Lara-Lemus R, Arvan P, Schuit FC, Wheeler MB, Chimienti F, and Rutter GA, Diabetes, 58, 2070-2083 (2009).

74) Lemaire K, Ravier MA, Schraenen A, Creemers JW, van de Plas R, Granvik M, van Lommel L, Waelkens E, Chimienti F, Rutter GA, Gilon P, in't Veld PA, and Schuit FC, Proc. Natl. Acad. Sci. USA, 106, 14872-14877 (2009).

75) Wenzlau JM, Juhl K, Yu L, Moua O, Sarkar SA, Gottlieb P, Rewers M, Eisenbarth GS, Jensen J, Davidson HW, and Hutton JC, Proc. Natl. Acad. Sci. USA, 104, 17040-17045 (2007).

76) Wenzlau JM, Liu Y, Yu L, Moua O, Fowler KT, Rangasamy S, Walters J, Eisenbarth GS, Davidson HW, and Hutton JC, Diabetes, 57, 2693-2697 (2008).

77) Palmiter RD, Cole TB, Quaife CJ, and Findley SD, Proc. Natl. Acad. Sci. USA, 93, 14934-14939 (1996).

78) Cole TB, Martyanova A, and Palmiter RD, Brain Res., 891, 253-265 (2001).

79) Salazar G, Craige B, Love R, Kalman D, and Faundez V, J. Cell Sci., 118, 1911-1921 (2005).

80) Salazar G, Love R, Werner E, Doucette MM, Cheng S, Levey A, and Faundez V, Mol. Biol. Cell, 15, 575-587 (2004).

81) Kantheti P, Qiao X, Diaz ME, Peden AA, Meyer GE, Carskadon SL, Kapfhamer D, Sufalko D, Robinson MS, Noebels JL, and Burmeister M, Neuron, 21, 111-122 (1998).

82) Lee JY, Cole TB, Palmiter RD, Suh SW, and Koh JY, Proc. Natl. Acad. Sci. USA, 99, 7705-7710 (2002).

83) Adlard PA, Parncutt JM, Finkelstein DI, and Bush AI, J. Neurosci., 30, 1631-1636 (2010).
84) Lonnerdal B, Annu. Rev. Nutr., 27, 165-177 (2007).

85) Kelleher SL, Seo YA, and Lopez V, Genes Nutr., 4, 83-94 (2009).

86) Chowanadisai W, Lonnerdal B, and Kelleher SL, J. Biol. Chem., 281, 39699-39707 (2006).

87) Huang L and Gitschier J, Nat. Genet., 17, 292-297 (1997).

88) Piletz JE and Ganschow RE, Science, 199, 181-183 (1978).

89) Kumanovics A, Poruk KE, Osborn KA, Ward DM, and Kaplan J, J. Biol. Chem., 281, 22566-22574 (2006).

90) Matsuura W, Yamazaki T, Yamaguchi-Iwai Y, Masuda S, Nagao M, Andrews GK, and Kambe T, Biosci. Biotechnol. Biochem., 73, 1142-1148 (2009).

91) Huang L, Kirschke CP, Zhang Y, and Yu YY, J. Biol. Chem., 280, 15456-15463 (2005)

92) Fukada T, Civic N, Furuichi T, Shimoda S, Mishima K, Higashiyama H, Idaira Y, Asada Y, Kitamura H, Yamasaki S, Hojyo S, Nakayama M, Ohara O, Koseki H, Dos Santos HG, Bonafe L, Ha-Vinh R, Zankl A, Unger S, Kraenzlin ME, Beckmann JS, Saito I, Rivolta C, Ikegawa S, Superti-Furga A, and Hirano T, PLoS ONE, 3, e3642 (2008).

93) Murakami $M$ and Hirano $T$, Cancer Sci., 99, 1515-1522 (2008).

94) Fukada $\mathrm{T}$ and Kambe T, Metallomics, DOI: 10.1039/ C1MT00011J

95) Yamasaki S, Sakata-Sogawa K, Hasegawa A, Suzuki T, Kabu K, Sato E, Kurosaki T, Yamashita S, Tokunaga M, Nishida K, and Hirano T, J. Cell Biol., 177, 637-645 (2007).

96) Hogstrand C, Kille P, Nicholson RI, and Taylor KM, Trends Mol. Med., 15, 101-111 (2009).

97) Taylor KM, Vichova P, Jordan N, Hiscox S, Hendley R, and Nicholson RI, Endocrinology, 149, 4912-4920 (2008).

98) Giunta C, Elcioglu NH, Albrecht B, Eich G, Chambaz C, Janecke AR, Yeowell H, Weis M, Eyre DR, Kraenzlin M, and Steinmann B, Am. J. Hum. Genet., 82, 1290-1305 (2008).

99) Maret W and Li Y, Chem. Rev., 109, 4682-4707 (2009).

100) Andreini C, Banci L, Bertini I, and Rosato A, J. Proteome Res., 5, 196-201 (2006).

101) Kim BE, Nevitt T, and Thiele DJ, Nat. Chem. Biol., 4, 176185 (2008).

102) Lill R, Nature, 460, 831-838 (2009).

103) Tottey S, Waldron KJ, Firbank SJ, Reale B, Bessant C, Sato K, Cheek TR, Gray J, Banfield MJ, Dennison C, and Robinson NJ, Nature, 455, 1138-1142 (2008).

104) Lyons TJ, Gasch AP, Gaither LA, Botstein D, Brown PO, and Eide DJ, Proc. Natl. Acad. Sci. USA, 97, 7957-7962 (2000). 